http://doi.org/10.4038/cjms.v45i1.4859

\title{
Minilap cholecystectomy - its place in the new millenium
}

W. R. D. Fonseka', R. D. Rajamanthri', S. M. Wijeyaratne: , A. H. Sheriffdeen ${ }^{3}$

The Ceylon Journal of Medical Science 2002; 45: 29-33

\begin{abstract}
Background: Although Laparoscopic cholecystectomy (LC) is considered to be the "gold standard" for gall stone disease, minilap cholecystectomy (MLC) using a small incision $2-5 \mathrm{cms}$ in length has gained popularity as an alternative technique.
\end{abstract}

This paper describes a new technique for this operation and compares outcome parameters for a matched group of patients undergoing LC or MLC.

Methods: A prospective analysis of outcome measures on 34 patients undergoing LC and 38 patients undergoing MLC was compared.

Results: There was no statistical difference in day of discharge from hospital, analgesic requirements, oral intake of solids, time to resume normal duties, wound infections and overall patient satisfaction when the two groups were compared using the chi square test.

Conclusion: MLC is a safe, compatable operation giving the same post operative outcome results compared to LC.

Key words: Laparoscopic cholecystectomy, minilap cholecystectomy, small incision cholecystectomy.

\section{Introduction}

Open Cholecystectomy (OC) was first performed in 1882 by Carl Langenbuch using a $T$ shaped incision the horizonal line made parallel to the liver margin (1). Since then several incisions for cholecystectomy have been described including the subcostal, midline and paramedian incisions
(2). The first laparoscopic cholecystectomy (LC) was performed by a German Surgeon, Erich Muhe in 1985 (3). This procedure has now become the standard and most commonly performed operative technique for gall stone disease. However to practice this technique one needs capital investment as the instruments are expensive, further expenditure for expensive consumables and further recurrent expenditure for repair or replacement of delicate instruments. Moreover, the learning curve for this procedure is often steep and could be prolonged compared to the conventional open technique.

The advantages of $L C$ over $O C$ include minimum length of incisions, less post operative pain, early discharge from hospital and early return to normal duties (4).

Over the last 10 years Minilap Cholecystectomy (MLC) using small incisions between $2-5 \mathrm{~cm}$ have been gaining popularity in the Western World (4). These patients too have been shown to enjoy the same benefits of less pain, minimum hospital stay and early return to work. Most authors use especially adapted instruments, devices and accessories to perform this operation $(5,6)$. The authors have in their unit carried out MLC using instruments available in any general surgical operating theatre.

\section{Methods}

This study was carried out on patients admitted for cholecystectomy over an 18 month period from Jan. 1999 to the Professorial Surgical Unit of the National Hospital of Sri Lanka, Colombo.

1. Senior Registrar, University Surgery Unit,

2. Senior Lecturer of Surgery, 3. Professor of Surgery, Faculty of Medicine, University of Colombo. 
All patients were confirmed to have gall stones by ultra sound scan examination. Patients with complications such as acute cholecystitis, cholangitis, jaundice and common bile duct stones were excluded from the study.

A total of 72 patients were randomly divided into the two groups LC 34 (47.3\%) and MLC $38(52.7 \%)$. Informed consent was obtained from all patients. Trained consultant surgeons performed the operations. Every patient had diclofenac sodium suppositories $(100 \mathrm{mg}$ ) inserted at the end of the operation.

Pain was recorded on a visual pain scale grades $0-I V(0=$ no pain, $I=$ mild, $I=$ moderate, $I I=$ severe, IV=unbearable pain).

All patients were recalled during the study and the balance data was recorded on a form, prior to examination.

\section{Results}

The patients were matched for age, sex, body mass index and co morbid illnesses in both LC and MLC groups (Figure 1).

On post operative day one, $26(86.7 \%)$ and 31 (81.2\%) patients of the LC and MLC groups were dischar-ged from hospital $(p>0.5)$.

Post operative analgesics weie not required by any from $L C$ group and by $2(5 \%)$ from the MLC group ( $p>0.5)$.

All patients from the LC group and $36(95 \%)$ from MLC group had a light to normal diet on day one post surgery ( $p>0.5)$.

Twenty three (88\%) from LC and $32(84 \%)$ from MLC had resumed normal duties by the tenth day post surgery $(p>0.5)$.

There was no recorded wound infection in the LC group but one patient (3\%) in the MLC group developed infection ( $p>0.0 .5$ ).

With regard to overall satisfaction over the surgical procedure $25(96 \%)$ in the LC group and $36(95 \%)$ in the MLC group were satisfied with the outcome and their expectations $(p>0.5)$.
There was no statistical significance in the outcome measurements in any of the variables studied (Figure 2).

\section{Discussion}

The procedure of open cholecystectomy using a small incision is widely known. Dubois and Berthelot described this operation in 1982 (8) and other reports have appeared in the literature since then $(1,6,7)$. Since the view is restricted and the lighting is difficult to focus into the cut depths of the wound special instruments such as the illuminated stabilizer, ring retractors (5), lighted retractor (6), special head lamps (6) and routine use of insulated forceps have been described.

We are in this paper describing a technique which has the following features.

(i). Placement of the incision is not nearer the midline as many surgeons believe it should be. It should be more lateral, the mid point being placed approximately halfway between the tip of the fundus of the gih costal cartilage and midline. This gives easy access to the fundus of the gall bladder and also enables the junction of the cystic and common bile duct to be visualized.

(ii). No special instruments or retractors are used.

(iii). The use of the large gauze towel (lap pad) inside the peritoneal cavity is the key to this approach. It helps to display the gall bladder and its anatomy by keeping away bowel and omentum, thus making it easier to focus the overhead lamp to the operation site. The gauze pad is moved about appropriately depending on the stage of the operation to demonstrate first the fundus, next Hartman's pouch and Calot's triangle and lastly by moving it medially to push away the fat of the ligamentum teres to display the cystic duct.

Whatever method is used it has proved safe in experienced hands. We have not found difficulty in exploring the common bile duct when indicated, without enlarging the incision. 
Figure 1. Concordance according to Age, Sex, BMI and Co-morbidity

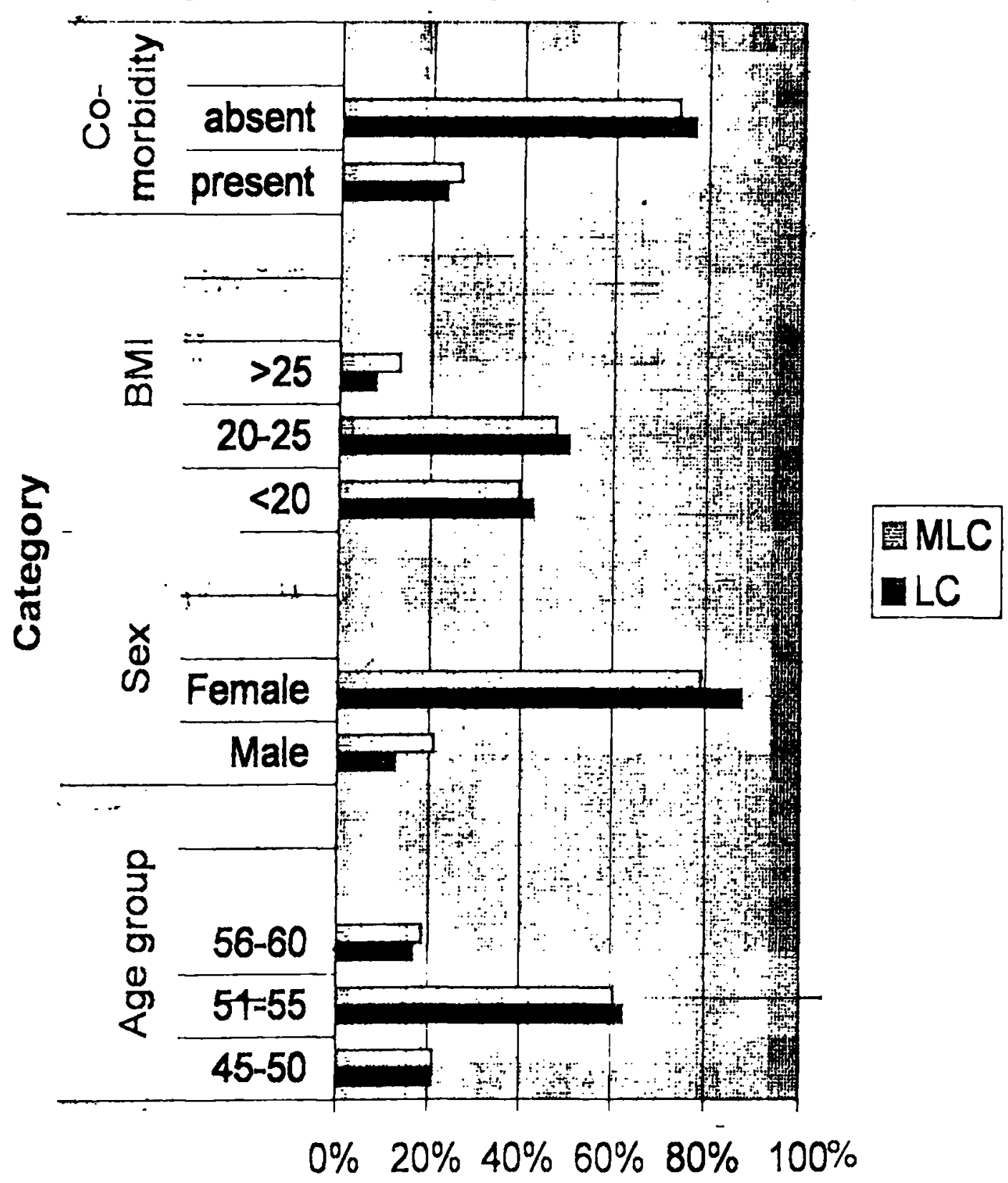

*There is no significant difference between groups.

$M L C=$ Minilap cholecystectomy $; \mathrm{BMI}=$ Body mass inde $x$

LC = Laparoscopic cholecystectomy 


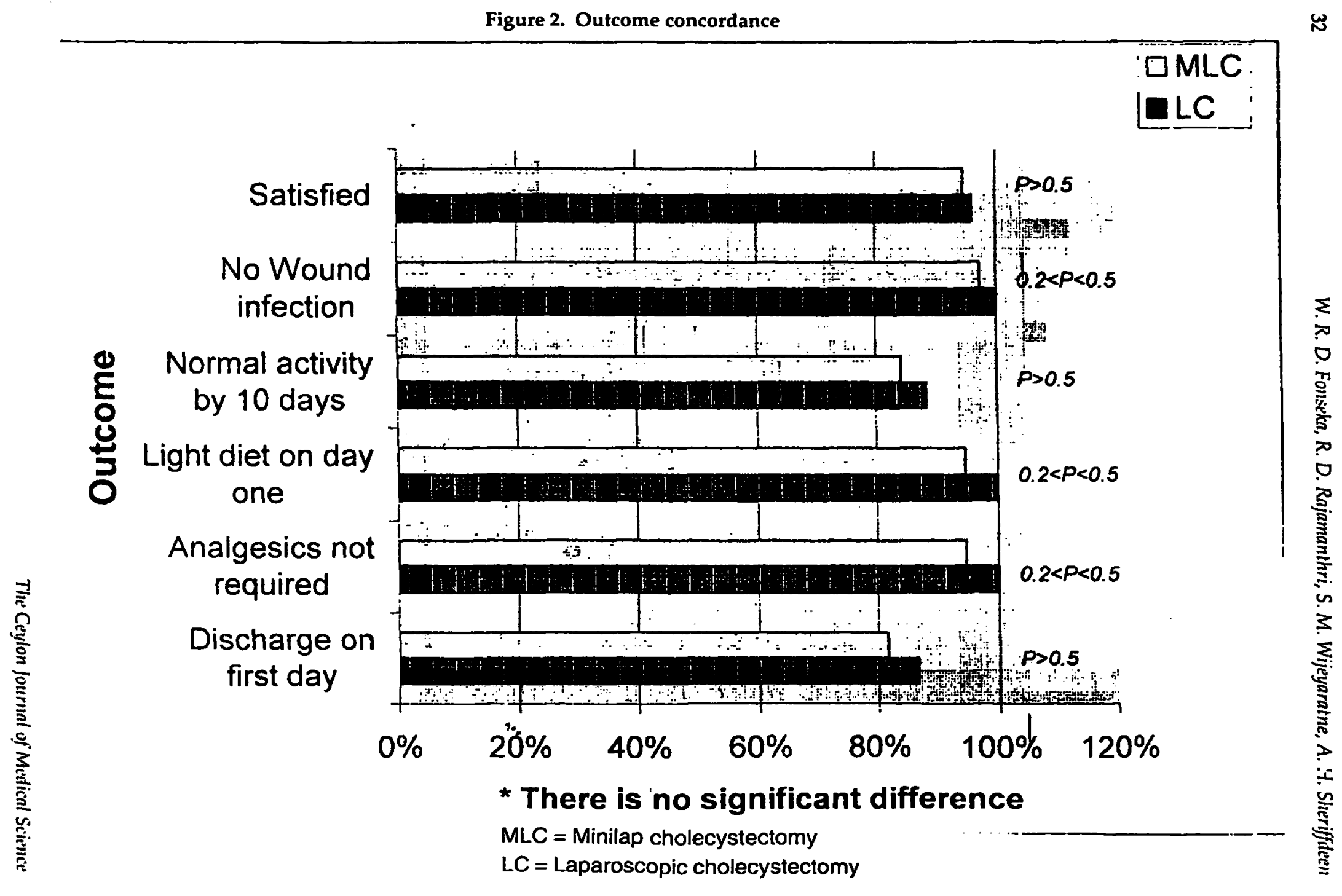


The outcome after surgery shows no difference in the parameters evaluated.

We agree with Sharma et al (6) that this is an operation that should be popularized in the developing world. Although he believes that it is difficult to train juniors, we have found that the assistant can follow the steps of the operation described by us and very soon gain the confidence to attempt it by oneself.

\section{References}

1. Dwyer P.J.O., Murphy J.J., Higgins N. Cholecystectomy through $5 \mathrm{~cm}$ subcostal incision. British Journal of Surgery 1990; 77: 1189-1190.

2. Maingot $R$. Abdominal operations vol $17^{\text {th }}$ Ed. New York, Appleton Century - Crofits 1037-1055.

3. Reynolds W. Jr. The first Laparoscopic Cholecystectomy. Journal of the Society of Laparoendoscopic Surgeons 2001; 5: 89-94.
4. Cameron J.L., Gadacz T.R. Laparoscopic Cholecystectomy. Annals of Surgery 1991; 2131: 1-2.

5. Russell R.C.G., Shankar S. The stabilized ring retractor: a technique for cholecystectomy. British Journal of Surgery 1987; 74: 826.

6. Sharma A.K., Rangan H.K., Choubey R.P. Mini-Lap cholecystectomy: a viable alternative to laparoscopic cholecystectomy for the third world? Australian and New Zealand Journal of Surgery 1998; 68: 774-777.

7. Sheriffdeen A.H. Minilap cholecystectomy. Abstracts of International Surgical Week of the International Surgical Society 1993; Abstr No. 1040: 5.

8. Dubois F., Berthelot B. Cholecystectomie per mini laparotomie Nouv. Press Med. 1982; 11: 1139-1141. (English abstract) 